\title{
Upper gastrointestinal bleeding in patients with liver cirrhosis, Is the difference of clinical outcomes depend on the source?
}

Mohamed Sorour Mohamed ( $\sim$ doctor037@yahoo.com )

Zagazig University Faculty of Human Medicine https://orcid.org/0000-0002-5967-5315

Marwan N Elgohary

Zagazig University Faculty of Human Medicine

Mohamed A A Bassiony

Zagazig University Faculty of Human Medicine

Amr Shaaban Hanafy

Zagazig University Faculty of Human Medicine

Research article

Keywords: cirrhosis, variceal, bleeding, gastrointestinal, liver, non-variceal, peptic ulcer

Posted Date: January 20th, 2020

DOI: https://doi.org/10.21203/rs.2.21312/v1

License: (c) (i) This work is licensed under a Creative Commons Attribution 4.0 International License.

Read Full License 


\section{Abstract}

Background and Study Aims

Acute upper gastrointestinal bleeding (UGIB) is the most common gastroenterological emergency in patients with cirrhosis; It increases the hospital length of stay (LOS), and Chance of 30-day hospital readmission. It has not been clarified if there is a difference in the prognosis of UGIB in cirrhosis depending on the source of bleeding. We aimed to investigate clinical outcomes in patients with cirrhosis with either acute variceal bleeding (AVB) or non-variceal bleeding (NVB) and risk factors for prolonged hospital LOS in both groups.

Patients and Methods

From July 2016 to January 2017, all adult eligible patients hospitalized with cirrhosis and UGIB were enrolled in the retrospective study, we assessed clinical outcomes in both groups and factors associated with prolonged hospital LOS.

Results

Of the 608 patients included in the study, 416 had variceal and 192 non-variceal bleeding. Mortality was higher in AVB group compared to NVB $(12.5 \%$ vs. $8.3 \%, P=0.023)$. There was a trend towards increased the length of hospital stay for those who had an AVB compared to NVB $(5.84 \pm 2.16$ vs. $4.33 \pm 1.18$, $\mathrm{p}=0.001)$. Rate of hospital Readmission was also higher in the AVB group. Risk factors for prolonged hospital LOS were in hospital rebleeding, presence of Hepatic encephalopathy or ascites, higher MELD score and Patients with child score B, C.

Conclusion

Patients with cirrhosis and AVB have higher mortality rate, longer hospital LOS and re-hospitalization rate than those with NVB.

\section{Background}

Acute upper gastrointestinal bleeding (UGIB) is the most common gastroenterological emergency in patients with cirrhosis and correlated with significant morbidity and mortality $[1,2]$. Acute variceal bleeding (AVB) is the leading cause of UGIB in cirrhosis and account for up to $70 \%$ of all cases[3,4], while non variceal bleeding (NVB) is a considerable cause of UGIB and responsible for the remaining cases, with the most frequent being peptic ulcer disease (PUD)[5]. In recent years significant amelioration in the therapeutic management of UGIB and improvement of hemostatic therapies resulted in a reduction of mortality and improvement of prognosis whether the cause is variceal $[6,7]$ or non-variceal $[7,8]$

Observational studies have demonstrated the higher mortality rate among patients with a bleeding Peptic ulcer with cirrhosis than in those without liver disease $[9,10]$. Risk factors that may be implicated in the 
higher mortality from UGIB in cirrhosis were the severity of liver disease, the alternation in the coagulation process, severity of the bleeding attack and the associated comorbidities $[7,10,11]$.

Furthermore, UGIB in cirrhosis increases the hospital length of stay (LOS), Chance of 30-day hospital readmission[12], spending on healthcare. However, it has not been clarified if there is a difference in the prognosis of UGIB in cirrhosis depending on the source of bleeding. Therefore in this study, we aimed to investigate clinical outcomes in patients with cirrhosis with either AVB or NVB and risk factors for prolonged hospital LOS in both groups.

\section{Methods}

This study was a retrospective cohort study that included all adults (age $\geq 18$ years) cirrhotic patients admitted with upper GI bleeding to Internal medicine gastroenterology unit at Zagazig University Hospital from July 2016 to January 2017; Cirrhosis was diagnosed by clinical, biochemical and imaging studies or by previous liver biopsy.

Patients were excluded if they had one or more of the following criteria: death before endoscopy due to severe bleeding, those who receive supportive therapy only or discharged before endoscopy, and patients with incomplete medical records.

\section{Study Design}

Emergency upper GI endoscopy was done for all patients included in the study after stabilization, Clinical outcomes were compared between the acute variceal bleeding group and non-variceal bleeding by a retrospective analysis of records of clinical, laboratory and endoscopic data of the patients

Clinical outcomes assessed included the length of hospital stay, packed RBCs transfusion rate, inhospital Re-bleeding, the need for repeating endoscopy during admission, the re-hospitalization rate within 30 days from admission and in-hospital mortality.

The data included from the medical records were:

(a) baseline characteristics of patients - age, sex, smoking history, medication history (NSAID, PPI, Beta Blocker......) and co-morbidities.

(b) clinical presentation of patient including: Symptom of presentation (hematemesis, melena, hematochezia, syncope, Hepatic encephalopathy), patients vital signs at time of admission, clinical features of liver decompensation

(c) hospitalization records - time of admission, upper Gl endoscopy and discharge, hospital Length of Stay, medication received during admission, the need for re endoscopy, packed RBCs transfusion and mortality rate during hospitalization; 
(d) Investigations details - CBC, serum albumin, total bilirubin, international normalized ratio (INR), creatinine, blood urea nitrogen, sodium and endoscopy details: the presence of varices, grades, gastric or duodenal ulcers, other sources of UGIB. (F) Re-hospitalization rate within 30 days was also recorded

Furthermore, we calculated for all included patients FIB4 score as an indicator for liver fibrosis state[13] and scores reflecting liver function state including MELD [14] and child score[15,16]. Glasgow-Blatchford Score[17], AIMS65 score[18] and complete rockall sore[19] were also calculated as prognostic scores for mortality, hospital LOS.

Esophageal varices were classified according to Modified Paquet classification[20] to Grade 1: Varices extending just above the mucosal level, Grade 2: Varices projecting by one-third of the luminal diameter and not compressed with air insufflation, Grade 3: Varices projecting up to $50 \%$ of the luminal diameter and in contact with each other.

Non variceal bleeding was defined as all other causes of Upper GI Bleeding: bleeding Peptic ulcer (diagnosed according to international consensus when endoscopy reveal an ulcer with active spurting (Forrest 1A), Active oozing (Forrest 1B), Non-bleeding visible vessel (Forrest 2A), Adherent clot (Forrest 2B), Flat pigmented spot(Forrest $2 \mathrm{C}$ ) or Clean ulcer base(Forrest $\mathrm{C})[21]$,esophagitis or gastritis, portalhypertensive gastropathy, , mallory-weiss tear...etc .

\section{Statistical analysis}

All data were statistically analyzed using SPSS version 20 for Windows (SPSS Inc., Chicago, USA). Quantitative data were expressed as the mean \pm SD. Qualitative data were expressed as absolute frequencies (number) \& (percentage). Tests of normality as Levene's test, Shapiro Wilk's test and inspection of their histograms and box plots were performed.

Sensitivity/specificity and positive/negative predictive values for the non-invasive diagnosis of fibrosis were assessed considering liver stiffness as the reference.

All variables with $\mathrm{P}<0.05$ were considered statistically significant.

\section{Results}

Seven hundred and thirty-four patients with cirrhosis were presented to the hospital with upper GI bleeding during the study period. From them, 608 patients with cirrhosis were enrolled in the study as shown in Fig. 1.416 bleed from esophageal varices and 192 patients diagnosed as non-variceal bleeding. The baseline characteristics of patients in both groups are summarized in Table 1 . The mean age of patients with NVB was significantly higher $(52.3 \pm 13.3)$ compared to those with AVB $(48.1 \pm 12.8)(p=$ 0.001). $32.2 \%$ of NVB patients were using ASA or NSAIDs compared to only $15.1 \%$ of AVB patients ( $p=$ 
0.001). While patients with NVB had lesser use of PPI before admission (29.5\%) compared to AVB (35.4\%), $P=0.04$, Patients with AVB were more likely to have a history of previous bleeding episodes $(37.7 \%$ vs. $22.3 \%$ of NVB group, $P=0.009)$

Table 1

Baseline characteristics of the study population

\begin{tabular}{|llll|}
\hline & $\begin{array}{l}\text { Variceal Bleeding } \\
\text { Group } \\
(\mathbf{N}=\mathbf{4 1 6})\end{array}$ & $\begin{array}{l}\text { Non-Variceal Bleeding } \\
\text { Group } \\
(\mathbf{N}=192)\end{array}$ & P Value \\
\hline Age, mean \pm SD, years & $48.1 \pm 12.8$ & $52.3 \pm 13.3$ & 0.001 \\
\hline Male, n, (\%) & $289(69.5 \%)$ & $127(66.1 \%)$ & 0.416 \\
\hline Smoking & $49(11.8 \%)$ & $31(16.1)$ & 0.160 \\
\hline Diabetes Mellitus & $162(38.9 \%)$ & $67(34.9 \%)$ & 0.09 \\
\hline NSAIDs or ASA use & $63(15.1 \%)$ & $62(32.2 \%)$ & 0.001 \\
\hline PPI use & $123(29.5 \%)$ & $68(35.4 \%)$ & 0.04 \\
\hline Beta Blocker treatment & $101(24.3 \%)$ & $57(29.7 \%)$ & 0.125 \\
\hline Previous bleeding episodes & $157(37.7 \%)$ & $43(22.3 \%)$ & 0.009 \\
\hline
\end{tabular}

Admission characteristics are summarized in Table 2. Patients with acute variceal bleeding were more likely to have lower hemoglobin level, platelet count, serum albumin and prolonged prothrombin time than the non-variceal bleeding group. 
Table 2

Clinical and laboratory parameters of the two groups at the time of admission

\begin{tabular}{|c|c|c|c|}
\hline & $\begin{array}{l}\text { Variceal Bleeding } \\
\text { Group } \\
(\mathrm{N}=416)\end{array}$ & $\begin{array}{l}\text { Non-Variceal Bleeding } \\
\text { Group } \\
(\mathrm{N}=192)\end{array}$ & P Value \\
\hline Heart Rate & $105 \pm 17$ & $107 \pm 19$ & 0.72 \\
\hline Systolic BP & $102 \pm 13$ & $104 \pm 15$ & 0.54 \\
\hline Respiratory rate & $17 \pm 3$ & $18.0 \pm 3$ & 0.91 \\
\hline Hg mean $\pm S D$ & $8.6 \pm 1.2$ & $9.3 \pm 1.5$ & 0.001 \\
\hline platelet & $101.5 \pm 44.3$ & $155 \pm 63.5$ & 0.001 \\
\hline INR & $1.78 \pm 0.51$ & $1.4 \pm 0.33$ & 0.001 \\
\hline Albumin & $2.7 \pm 0.56$ & $3.1 \pm 0.57$ & 0.001 \\
\hline Creatinine & $1.29 \pm 0.38$ & $1.2 \pm 0.43$ & 0.17 \\
\hline BUN (mmol/L), mean (SD) & $10.2(4.9)$ & $9.9(6.7)$ & 0.63 \\
\hline T. bilirubin & $1.8 \pm 1.1$ & $1.76 \pm 1$ & 0.331 \\
\hline MELD & $18 \pm 5.4$ & $10 \pm 3.1$ & 0.001 \\
\hline $\begin{array}{l}\text { CHILD score } \\
\text { A } \\
\text { B } \\
\text { C }\end{array}$ & $\begin{array}{l}64(15.4 \%) \\
192(46.2) \\
160(38.4)\end{array}$ & $\begin{array}{l}112(58 \%) \\
48(25 \%) \\
32(16.7 \%)\end{array}$ & 0.001 \\
\hline FIB4 & $6.57 \pm 5.3$ & $4.99 \pm 3.49$ & 0.001 \\
\hline Glasgow-Blatchford Score & $15 \pm 1.36$ & $13 \pm 1.72$ & 0.008 \\
\hline AIMS65 Score & $2.6 \pm 1.52$ & $2.2 \pm 1.44$ & 0.03 \\
\hline Rockall Score & $7.1 \pm 1.3$ & $6.4 \pm 1.6$ & 0.01 \\
\hline
\end{tabular}

Scoring parameters reflecting Liver function status at the time of admission revealed that $38.4 \%$ of patients with $A V B$ were child $C$ in contrast to $16.7 \%$ of the non-variceal bleeding group $(P=0.001)$, the severity of liver fibrosis checked by FIB4 score revealed that patients with AVB have significantly higher FIB 4 than NVB group. We have also found that AVB cohorts have significantly higher MELD score, Glasgow-Blatchford Score, AIMS65 Score and rockall score.

The differences between clinical outcomes of the two groups are summarized in Table 3 . The Mortality was significantly higher in patients presented with AVB compared to NVB group, $12.5 \%$ vs. $8.3 \%$ respectively, $P=0.023$. There was a trend towards increased the length of hospital stay for those who had an AVB compared to NVB $(5.84 \pm 2.16$ vs. $4.33 \pm 1.18, p=0.001)$. There was no significant difference 
between the two groups regarding requirement for packed RBCs transfusion and the requirement for repeated endoscopy for Re-bleeding within 72 hours from the initial bleeding episode, However the rate of hospital Readmission within 30 days of admission was significantly higher In AVB group (23.1\%) than NVB group (16.7\%) $(P=0.042)$.

Table 3

Clinical outcomes in patients with cirrhosis and upper GI bleeding

\begin{tabular}{|llll|}
\hline & $\begin{array}{l}\text { Variceal Bleeding } \\
\text { Group } \\
(\mathbf{N}=\mathbf{4 1 6})\end{array}$ & $\begin{array}{l}\text { Non-Variceal Bleeding } \\
\text { Group } \\
(\mathbf{N}=192)\end{array}$ & P Value \\
\hline Mortality & $52(12.5 \%)$ & $16(8.3 \%)$ & 0.023 \\
\hline REq. transfusion & $224(53 \%)$ & $94(49 \%)$ & 0.135 \\
\hline Bleeding, re-endoscopy within 72hrs & $64(15.26 \%)$ & $20(10.41 \%)$ & 0.088 \\
\hline Length of Stay & $5.84 \pm 2.16$ & $4.33 \pm 1.78$ & 0.001 \\
\hline Rehospitaliztion.30 days & $96(23.1 \%)$ & $32(16.7 \%)$ & 0.042 \\
\hline
\end{tabular}

The risk factors associated with prolonged hospital length of stay were evaluated in the two groups of patients (Table 4). Patients presented by hepatic encephalopathy or developed it during hospital admission had significantly prolonged Hospital LOS in Both AVB and NVB groups. The presence of ascites or the re-bleeding during hospital admission were also significant risk factors that influenced the hospital LOS. Other parameters that associated with prolonged hospital LOS were higher MELD score or Child score class B and C. 
Table 4

Hospital Length of stay among patients with cirrhosis and upper GI bleeding

\begin{tabular}{|c|c|c|c|c|}
\hline & $\begin{array}{l}\text { Variceal Bleeding } \\
\text { Group } \\
(\mathrm{N}=416)\end{array}$ & P Value & $\begin{array}{l}\text { Non-Variceal Bleeding } \\
\text { Group } \\
(\mathrm{N}=192)\end{array}$ & P Value \\
\hline $\begin{array}{l}\text { Age } \\
\bigotimes 50 \text { years } \\
\geq 50 \text { years }\end{array}$ & $\begin{array}{l}5.67 \pm 2.72 \\
5.93 \pm 1.83\end{array}$ & 0.09 & $\begin{array}{l}4.12 \pm 1.26 \\
4.51 \pm 2.32\end{array}$ & 0.15 \\
\hline $\begin{array}{l}\text { Sex } \\
\text { Male } \\
\text { female }\end{array}$ & $\begin{array}{l}5.74 \pm 1.9 \\
5.87 \pm 2.2\end{array}$ & 0.77 & $\begin{array}{l}4.2 \pm 1.9 \\
4.3 \pm 1.7\end{array}$ & 0.43 \\
\hline $\begin{array}{l}\text { DM } \\
\text { Yes } \\
\text { No }\end{array}$ & $\begin{array}{l}5.82 \pm 2.81 \\
5.76 \pm 1.72\end{array}$ & 0.36 & $\begin{array}{l}4.61 \pm 1.65 \\
3.9 \pm 2.64\end{array}$ & 0.14 \\
\hline $\begin{array}{l}\text { NSAIDs use } \\
\text { Yes } \\
\text { No }\end{array}$ & $\begin{array}{l}5.62 \pm 1.75 \\
5.89 \pm 3.14\end{array}$ & 0.65 & $\begin{array}{l}4.42 \pm 1.92 \\
4.26 \pm 0.96\end{array}$ & 0.26 \\
\hline $\begin{array}{l}\text { Beta Blocker use } \\
\text { Yes } \\
\text { No }\end{array}$ & $\begin{array}{l}5.35 \pm 2.91 \\
5.87 \pm 2.13\end{array}$ & 0.08 & $\begin{array}{l}3.98 \pm 2.69 \\
4.23 \pm 1.65\end{array}$ & 0.13 \\
\hline $\begin{array}{l}\text { previous bleeding episode } \\
\text { Yes } \\
\text { No }\end{array}$ & $\begin{array}{l}5.49 \pm 1.82 \\
5.75 \pm 3.12\end{array}$ & 0.49 & $\begin{array}{l}4.61 \pm 1.18 \\
4.15 \pm 1.37\end{array}$ & 0.68 \\
\hline $\begin{array}{l}\text { Encephalopathy } \\
\text { Yes } \\
\text { No }\end{array}$ & $\begin{array}{l}6.47 \pm 2.39 \\
4.48 \pm 1.74\end{array}$ & 0.009 & $\begin{array}{l}5.42 \pm 2.21 \\
3.63 \pm 1.47\end{array}$ & 0.004 \\
\hline $\begin{array}{l}\text { Ascites } \\
\text { Yes } \\
\text { No }\end{array}$ & $\begin{array}{l}6.24 \pm 2.81 \\
4.98 \pm 1.32\end{array}$ & 0.003 & $\begin{array}{l}4.92 \pm 2.38 \\
3.47 \pm 2.11\end{array}$ & 0.02 \\
\hline $\begin{array}{l}\text { Re-bleeding at hospital } \\
\text { Yes } \\
\text { No }\end{array}$ & $\begin{array}{l}6.82 \pm 2.61 \\
3.95 \pm 2.19\end{array}$ & 0.001 & $\begin{array}{l}6.22 \pm 1.88 \\
3.87 \pm 1.62\end{array}$ & 0.001 \\
\hline $\begin{array}{l}\text { MELD } \\
\otimes 10 \\
\geq 10\end{array}$ & $\begin{array}{l}4.87 \pm 1.48 \\
5.93 \pm 1.87\end{array}$ & 0.05 & $\begin{array}{l}3.87 \pm 1.29 \\
4.53 \pm 1.67\end{array}$ & 0.008 \\
\hline $\begin{array}{l}\text { CHILD score } \\
\text { A } \\
\text { B } \\
\text { C }\end{array}$ & $\begin{array}{l}3.87 \pm 1.52 \\
5.73 \pm 1.39 \\
6.93 \pm 2.57\end{array}$ & 0.007 & $\begin{array}{l}3.16 \pm 1.28 \\
4.78 \pm 1.91 \\
5.85 \pm 2.37\end{array}$ & 0.002 \\
\hline
\end{tabular}


Liver cirrhosis is a major public health problem in Egypt because of the high HCV seroprevalence which was estimated to be $14.7 \%$ among the $15-59$ years age group[22]. Acute UGIT bleeding is common in patients with liver cirrhosis and is associated with significant morbidity and mortality. Early detection of the source of UGIT bleeding help to ameliorate management and clinical outcomes[23]. In the present study, we found that the mortality of patients with cirrhosis and AVB is higher than those with NVB. The risk of prolonged hospital LOS and the re-hospitalization rate within 30 days were significantly higher in patients AVB than those with NVB.

The higher mortality rate in patients with AVB than NVB is in agreement with previous studies suggested that patients with cirrhosis and AVB showed a high mortality rate $[24,25]$. The high mortality in AVB may be related to the severity of presentation, rate of in-hospital re-bleeding, and the different parameters reflecting the more derangement of liver function in patients AVB and cirrhosis than NVB group such as MELD and Child-Pugh scores.

Although in our study the patients with AVB are younger than those with NVB they are more likely to have a history of bleeding episodes, higher Glasgow-Blatchford Score, AIMS65 Score and advanced hepatic cirrhosis. All these factors help to clarify our observation of longer hospital LOS in patients with AVB than those with NVB. This is consistent with other studies which have documented the shorter hospital LOS in cirrhotic patients if the source of upper GIT bleeding is not variceal[3,23].

In this study, certain factors were associated with increased Hospital LOS in the AVB group and NVB group as well. In-hospital re-bleeding is the main risk factor noted in both groups which is in agreement with other studies which have shown that in-hospital re-bleeding within 72 hours of admission increase the risk of ICU admission, hospital LOS and overall mortality [3,4,11], Other factors include the presence of ascites, experiences of hepatic encephalopathy during admission, high MELD score and advanced Child score. On the other hand hospital LOS was not related to Age, Gender, The use of NSAIDs or Beta blocker, presence of DM or history of previous bleeding episodes in both groups.

Early differentiation of the source of upper GI bleeding whether variceal or non-variceal help for rapid accurate etiology-guided management and prediction of patients prognosis and clinical outcomes. In our study noninvasive predictor tests which correlates with hospital LOS, risk of re-bleeding and mortality, such as AIMS65 Score and glasgow-blatchford score (GBS) were higher in the AVB group than NVB group. Furthermore when we assess the risk of mortality by complete rockall rcore was also significantly higher in AVB cohort. This observation is consistent with preliminary findings of our study that AVB patients have poorer clinical outcomes and higher mortality than NVB patients

Although our study is a single-center study, the inclusion of all eligible patients admitted to our tertiary hospital during the study period and the relatively large number of included patients represent the strength of our study

\section{Conclusion}


This study showed that patients with cirrhosis and AVB have higher mortality rate, longer hospital LOS and re-hospitalization rate than those with NVB. In-hospital bleeding and the severity of liver decompensation were associated with prolonged hospital LOS in both groups.

\section{Abbreviations}

UGIB : upper gastrointestinal bleeding

LOS : length of stay

AVB : acute variceal bleeding

NVB : non-variceal bleeding

$\mathrm{GI} \quad: \quad$ gastrointestinal

GBS : glasgow-blatchford score

\section{Declarations}

\section{Ethics approval and consent to participate}

The study approved from faculty of medicine Zagazig university ethical committee

Consent for publication

Not applicable

\section{Availability of data and materials}

The datasets used and/or analysed during the current study are available from the corresponding author on reasonable request

\section{Competing interests}

The authors declare that they have no competing interests

\section{Funding}

The research is self-funded

\section{Authors' contributions}

Mohamed Sorour Mohamed: research methodology 
Mohamed Sorour Mohamed, Marwan N Elgohary, Mohamed A A Bassiony: clinical analysis, data collection

Amr S Hanafy and Mohamed Sorour Mohamed: statistical analysis and revision

\section{Acknowledgements}

Not applicable' for that section

\section{References}

[1] Sostres C, Lanas A. Epidemiology and Demographics of Upper Gastrointestinal Bleeding:

Prevalence, Incidence, and Mortality. Gastrointest Endosc Clin N Am 2011;21:567-81.

doi:10.1016/j.giec.2011.07.004.

[2] D'Amico G, De Franchis R, Cooperative Study Group. Upper digestive bleeding in cirrhosis. Posttherapeutic outcome and prognostic indicators. Hepatology 2003;38:599-612. doi:10.1053/jhep.2003.50385.

[3] Tandon P, Bishay K, Fisher S, Yelle D, Carrigan I, Wooller K, et al. Comparison of clinical outcomes between variceal and non-variceal gastrointestinal bleeding in patients with cirrhosis. J Gastroenterol Hepatol 2018;33:1773-9. doi:10.1111/jgh.14147.

[4] Afessa B, Kubilis PS. Upper gastrointestinal bleeding in patients with hepatic cirrhosis: clinical course and mortality prediction. Am J Gastroenterol 2000;95:484-9. doi:10.1111/j.15720241.2000.01772.x.

[5] Gabr MA, Tawfik MAE-R, El-Sawy AAA. Non-variceal upper gastrointestinal bleeding in cirrhotic patients in Nile Delta. Indian J Gastroenterol 2016;35:25-32. doi:10.1007/s12664-016-0622-7.

[6] Carbonell N, Pauwels A, Serfaty L, Fourdan O, Lévy VG, Poupon R. Improved survival after variceal bleeding in patients with cirrhosis over the past two decades. Hepatology 2004;40:652-9. doi:10.1002/hep.20339.

[7] Crooks C, Card T, West J. Reductions in 28-day mortality following hospital admission for upper gastrointestinal hemorrhage. Gastroenterology 2011;141:62-70. doi:10.1053/j.gastro.2011.03.048.

[8] Lau JY, Barkun A, Fan D, Kuipers EJ, Yang Y, Chan FK. Challenges in the management of acute peptic ulcer bleeding. Lancet 2013;381:2033-43. doi:10.1016/S0140-6736(13)60596-6.

[9] Holland-Bill L, Christiansen CF, Gammelager H, Mortensen RN, Pedersen L, Sørensen HT. Chronic liver disease and 90-day mortality in 21,359 patients following peptic ulcer bleeding-a Nationwide Cohort 
Study. Aliment Pharmacol Ther 2015;41:564-72. doi:10.1111/apt.13073.

[10] Leontiadis GI, Molloy-Bland M, Moayyedi P, Howden CW. Effect of comorbidity on mortality in patients with peptic ulcer bleeding: systematic review and meta-analysis. Am J Gastroenterol 2013;108:331-45; quiz 346. doi:10.1038/ajg.2012.451.

[11] Olmo JA de., Peña A, Serra MA, Wassel AH, Benages A, Rodrigo JM. Predictors of morbidity and mortality after the first episode of upper gastrointestinal bleeding in liver cirrhosis. J Hepatol 2000;32:1924. doi:10.1016/S0168-8278(01)68827-5.

[12] Seraj SM, Campbell EJ, Argyropoulos SK, Wegermann K, Chung RT, Richter JM. Hospital readmissions in decompensated cirrhotics: Factors pointing toward a prevention strategy. World $\mathrm{J}$ Gastroenterol 2017;23:6868-76. doi:10.3748/wjg.v23.i37.6868.

[13] Vallet-Pichard A, Mallet V, Nalpas B, Verkarre V, Nalpas A, Dhalluin-Venier V, et al. FIB-4: An inexpensive and accurate marker of fibrosis in HCV infection. comparison with liver biopsy and fibrotest. Hepatology 2007;46:32-6. doi:10.1002/hep.21669.

[14] Kamath PS, Kim WR. The model for end-stage liver disease (MELD). Hepatology 2007;45:797805. doi:10.1002/hep.21563.

[15] Child CG, Turcotte JG. Surgery and portal hypertension. Major Probl Clin Surg 1964;1:1-85.

[16] Pugh RNH, Murray-Lyon IM, Dawson JL, Pietroni MC, Williams R. Transection of the oesophagus for bleeding oesophageal varices. Br J Surg 1973;60:646-9. doi:10.1002/bjs.1800600817.

[17] Blatchford O, Murray WR, Blatchford M. A risk score to predict need for treatment for uppergastrointestinal haemorrhage. Lancet (London, England) 2000;356:1318-21. doi:10.1016/S01406736(00)02816-6.

[18] Saltzman JR, Tabak YP, Hyett BH, Sun X, Travis AC, Johannes RS. A simple risk score accurately predicts in-hospital mortality, length of stay, and cost in acute upper GI bleeding. Gastrointest Endosc 2011;74:1215-24. doi:10.1016/j.gie.2011.06.024.

[19] Rockall TA, Logan RF, Devlin HB, Northfield TC. Risk assessment after acute upper gastrointestinal haemorrhage. Gut 1996;38:316. doi:10.1136/GUT.38.3.316.

[20] Paquet KJ. Prophylactic Endoscopic Sclerosing Treatment of the Esophageal Wall in Varices - A Prospective Controlled Randomized Trial. Endoscopy 1982;14:4-5. doi:10.1055/s-2007-1021560.

[21] Forrest J., Finlayson ND., Shearman DJ. ENDOSCOPY IN GASTROINTESTINAL BLEEDING. Lancet 1974;304:394-7. doi:10.1016/S0140-6736(74)91770-X. 
[22] El-Zanaty F and AW. Egypt Demographic Health Survey 2008. Heal (San Fr 2009:463.

doi:10.1126/science.331.6020.996.

[23] Ardevol A, lbañez-Sanz G, Profitos J, Aracil C, Castellvi JM, Alvarado E, et al. Survival of patients with cirrhosis and acute peptic ulcer bleeding compared with variceal bleeding using current first-line therapies. Hepatology 2018;67:1458-71. doi:10.1002/hep.29370.

[24] Sanders DS, Carter MJ, Goodchap RJ, Cross SS, Gleeson DC, Lobo AJ. Prospective validation of the Rockall risk scoring system for upper $\mathrm{GI}$ hemorrhage in subgroups of patients with varices and peptic ulcers. Am J Gastroenterol 2002;97:630-5. doi:10.1111/j.1572-0241.2002.05541.x.

[25] Ismail FW, Mumtaz K, Shah HA, Hamid S, Abbas Z, Abid S, et al. Factors predicting in-hospital mortality in patients with cirrhosis hospitalized with gastro-esophageal variceal hemorrhage. Indian $\mathrm{J}$ Gastroenterol n.d.;25:240-3.

\section{Figures}

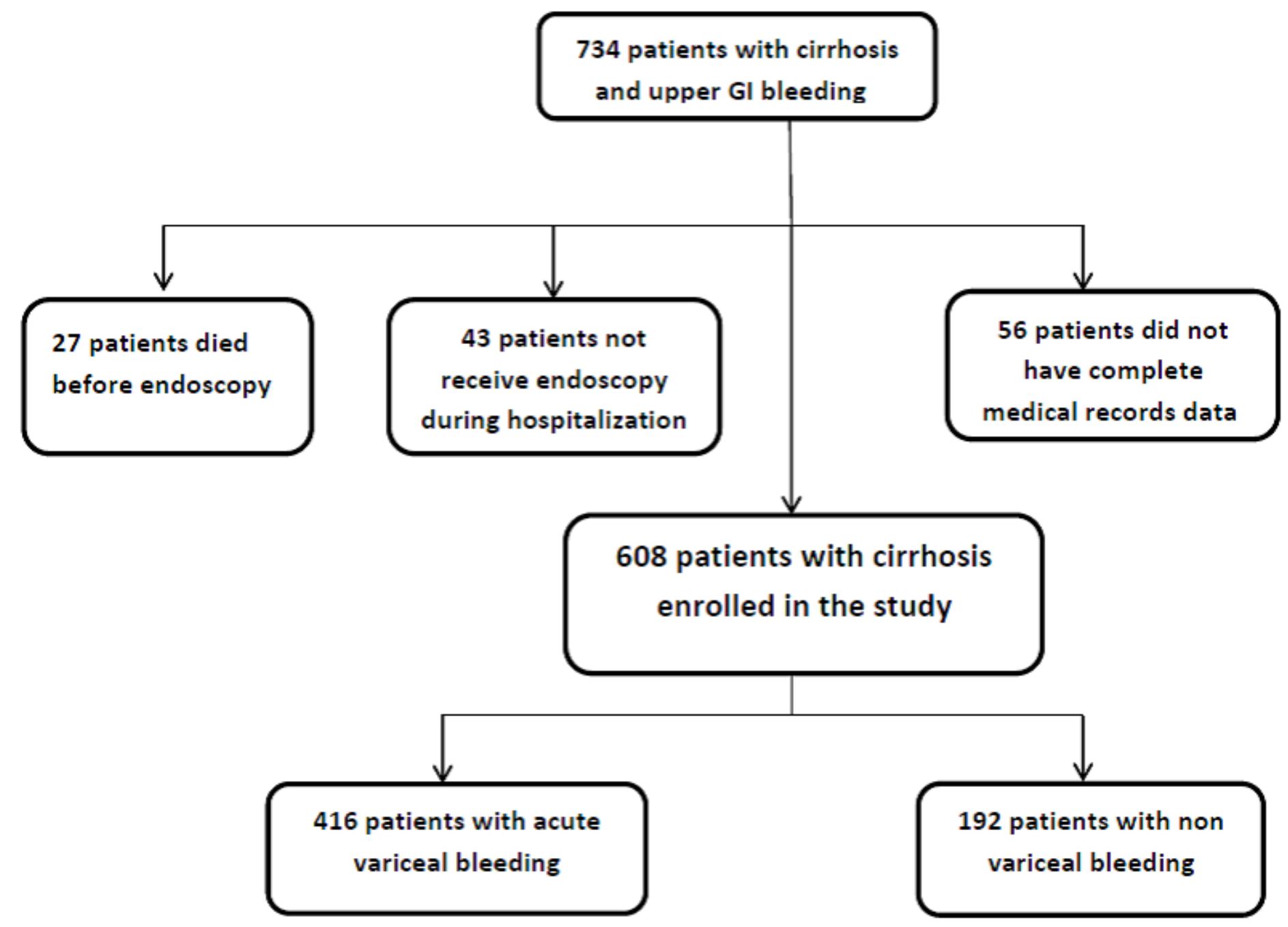


Figure 1

Flow chart for patients included in the study 